\title{
FDG-PET Imaging for Hodgkin and Diffuse Large B-Cell Lymphoma-An Updated Overview
}

\author{
Conrad-Amadeus Voltin ${ }^{1, *} \oplus$, Jasmin Mettler ${ }^{1}$, Jirka Grosse ${ }^{2}$, Markus Dietlein ${ }^{1}$, \\ Christian Baues $^{3}{ }^{\mathbb{D}}$, Christine Schmitz ${ }^{4}$, Peter Borchmann ${ }^{5}$, Carsten Kobe ${ }^{1}$ and Dirk Hellwig ${ }^{2}$ (D) \\ 1 Department of Nuclear Medicine, Faculty of Medicine and University Hospital Cologne, University of \\ Cologne, 50937 Cologne, Germany; jasmin.mettler@uk-koeln.de (J.M.); markus.dietlein@uk-koeln.de (M.D.); \\ carsten.kobe@uk-koeln.de (C.K.) \\ 2 Department of Nuclear Medicine, University Hospital Regensburg, 93053 Regensburg, Germany; \\ jirka.grosse@ukr.de (J.G.); dirk.hellwig@ukr.de (D.H.) \\ 3 Department of Radiation Oncology and Cyberknife Center, Faculty of Medicine and University Hospital \\ Cologne, University of Cologne, 50937 Cologne, Germany; christian.baues@uk-koeln.de \\ 4 Department of Hematology, West German Cancer Center (WTZ), University Hospital Essen, University of \\ Duisburg-Essen, 45147 Essen, Germany; christine.schmitz@uk-essen.de \\ 5 Department of Internal Medicine I, Center for Integrated Oncology Aachen-Bonn-Cologne-Dusseldorf (CIO \\ ABCD), Faculty of Medicine and University Hospital Cologne, University of Cologne, \\ 50937 Cologne, Germany; peter.borchmann@uk-koeln.de \\ * Correspondence: conrad-amadeus.voltin@uk-koeln.de; Tel.: +49-221-478-7534
}

Received: 14 January 2020; Accepted: 3 March 2020; Published: 5 March 2020

check for updates

\begin{abstract}
Since the mid-1990s, ${ }^{18}$ F-fluorodeoxglucose (FDG)-positron emission tomography (PET) in combination with computed tomography has come to play a prominent role in the management of malignant lymphomas. One of the first PET applications in oncology was the detection of lymphoma manifestations at staging, where it has shown high sensitivity. Nowadays, this imaging modality is also used during treatment to evaluate the individual chemosensitivity and adapt further therapy accordingly. If the end-of-treatment PET is negative, irradiation in advanced-stage Hodgkin lymphoma patients can be safely omitted after highly effective chemotherapy. Thus far, lymphoma response assessment has mainly been performed using visual criteria, such as the Deauville five-point scale, which became the international standard in 2014. However, novel measures such as metabolic tumor volume or total lesion glycolysis have recently been recognized by several working groups and may further increase the diagnostic and prognostic value of FDG-PET in the future.
\end{abstract}

Keywords: Hodgkin lymphoma; diffuse large B-cell lymphoma; positron emission tomography; staging; response assessment

\section{Introduction}

Hodgkin lymphoma is a hematologic malignancy with one of the best long-term outcomes after first-line treatment. Ongoing efforts to improve therapy effectiveness have resulted in a 5 -year relative survival rate of about $90 \%$ for patients diagnosed between the ages of 20 and 64 years [1]. Treatment is selected depending on individual factors and consists of chemotherapy alone or chemotherapy followed by irradiation [2]. Over the years, ${ }^{18}$ F-fluorodeoxyglucose (FDG)-positron emission tomography (PET) in combination with computed tomography (CT) has proved a valuable tool for detecting manifestations of lymphoma at diagnosis, and is nowadays considered state-of-the-art. On the basis of stage and other clinical risk indicators, Hodgkin lymphoma can be divided into three different risk-groups, these being early-favorable, early-unfavorable, and advanced disease. While the early stages commonly respond well to a combination of doxorubicin, bleomycin, vinblastine, 
and dacarbazine (ABVD), advanced Hodgkin lymphoma is more effectively treated with bleomycin, etoposide, doxorubicin, cyclophosphamide, vincristine, procarbazine, and prednisone (BEACOPP), for instance in its dose-escalated form (eBEACOPP) [3-7]. However, genotoxic treatment can lead to several complications and might be associated with increased long-term morbidity, including secondary malignancies and cardiovascular disease. A large survey among 1149 Hodgkin lymphoma survivors showed that optimal lymphoma control and primary cure are of utmost importance from the patient's perspective [8]. In advanced stage, these goals can be most effectively achieved through an intensive chemotherapy regimen. However, as the group of patients with advanced Hodgkin lymphoma includes individuals with very different risk profiles, a substantial proportion of them, around $60 \%$ to $70 \%$, would presumably be over-treated by eBEACOPP [9]. Biomarkers to assess the tumor under treatment are therefore of great importance for identifying those patients who respond very well to chemotherapy and in whom treatment intensity can be reduced without compromising the primary cure rate. On the other hand, individuals showing poor response might require escalation of therapy. A growing body of evidence strongly supports the use of FDG-PET for assessing changes in tumor metabolism during Hodgkin lymphoma treatment. As shown by large randomized trials, decisions regarding escalation [4] or de-escalation of therapy [3,7] can safely be based on PET results. The outstanding performance of FDG-PET in Hodgkin lymphoma most probably arises from its ratio of neoplastic to reactive microenvironment cells, which differs significantly from other lymphoma subtypes $[10,11]$.

Diffuse large B-cell lymphoma (DLBCL) represents the most common subtype of non-Hodgkin lymphoma, accounting for $30 \%$ to $40 \%$ of all newly diagnosed cases [12]. Despite significant advances in the management of this malignancy, cure rates are still generally lower than for Hodgkin lymphoma, with approximately one-third of all individuals failing front-line therapy. Due to its superior sensitivity in the detection of nodal and extra-nodal lymphoma manifestations, FDG-PET is strongly recommended for staging patients with DLBCL [13]. Moreover, several international trials have examined whether PET imaging may be used early during treatment to separate individuals needing therapy intensification from good responders, that is, candidates for de-escalation [14-18]. As standard treatment, patients receive six chemotherapy cycles of cyclophosphamide, doxorubicin, vincristine, and prednisone alongside the monoclonal antibody rituximab (R-CHOP). Unlike early-stage disease, which can be considered for brief chemotherapy [19], advanced DLBCL with high risk, as defined by the International Prognostic Index, may require intensified treatment, including central nervous system prophylaxis $[20,21]$. The role of radiotherapy is still under discussion in DLBCL. Large randomized trials have indicated that subsequent consolidative irradiation of former bulky sites in advanced-stage patients may have a positive effect on outcome [22,23].

This article presents an overview of current PET applications in Hodgkin lymphoma and DLBCL. Furthermore, recent developments regarding imaging-directed therapy concepts for these individuals as well as future directions are discussed.

\section{Initial Staging}

Accurate and reproducible staging is crucial to determine the most appropriate treatment in both Hodgkin lymphoma and DLBCL. With high sensitivity for involved lymph nodes and extra-nodal disease, FDG-PET has become established as the standard of care for assessing all FDG-avid lymphomas, and is recommended by the 2014 Lugano criteria [24], which updated the established Ann Arbor classification [25].

\subsection{Hodgkin Lymphoma}

In the randomized multi-center U.K. RATHL trial [26], FDG-PET upstaged 14\% of Hodgkin lymphoma patients, mainly due to bone marrow involvements, which had not been identified by biopsy. Downstaging occurred in $6 \%$ of cases, particularly as a result of splenomegaly with normal FDG uptake or enlarged but PET-negative lymph nodes. Several studies on Hodgkin lymphoma demonstrated that FDG-PET has a sensitivity even higher than biopsy for detecting bone marrow 
involvement. While bone marrow biopsy diagnoses about $5 \%$ of involvements, focal skeletal FDG lesions are seen in up to $20 \%$ of newly diagnosed patients [27-31]. The largest head-to-head comparison to date showed a sensitivity and negative predictive value (NPV) of 95\% and 99.9\%, respectively, for FDG-PET when taking positive biopsy as the reference standard [32]. Moreover, Pedersen et al. reported a significantly inferior progression-free survival (PFS) for individuals with focal bone lesions, independent of chemotherapy type [33]. Based on the high level of scientific evidence, there is a broad consensus that bone marrow biopsy can be abandoned in Hodgkin lymphoma patients staged by FDG-PET. Importantly, diffusely increased skeletal FDG uptake is rarely associated with positive biopsy results, and should therefore not be considered a sign of lymphoma [34].

In the vast majority of patients with Hodgkin lymphoma, PET-detected skeletal lesions do not influence therapy selection, as only $<1 \%$ of otherwise early-stage individuals were found to have bone marrow involvement on FDG-PET [32]. In a study of Picardi et al., PET-based staging at least resulted in an improved event-free survival compared to a historical cohort. However, an improved overall survival (OS) could not be shown by a randomized prospective trial [35].

\section{2. $D L B C L$}

A retrospective analysis on DLBCL by Fuertes et al. reported upstaging in $15 \%$ of patients after FDG-PET [36]. Further studies focusing on subjects with DLBCL found similar results for non-Hodgkin lymphoma and rarely observed PET-based downstaging [37,38]. It should be taken into consideration that FDG-PET has proven to be less sensitive for identifying bone marrow involvements in aggressive non-Hodgkin lymphoma as compared to Hodgkin lymphoma $[39,40]$. On the basis of data from one Canadian and two Danish centers, Alzahrani et al. determined a sensitivity and NPV of $60 \%$ and $91 \%$, respectively [41]. Similar findings emerged from a pooled analysis of the PETAL and OPTIMAL $>60$ study cohorts [42]. In this context, the limited sensitivity of PET can most likely be explained by the observation that positive bone marrow biopsy results of DLBCL patients are quite frequently associated with diffusely increased skeletal FDG uptake. On the other hand, the use of biopsy seems justified only when results could have a direct impact on treatment selection, for example in patients with limited-stage disease and lack of further risk factors. Importantly, bone marrow biopsy should be omitted in all individuals where involvement has already been proven with FDG-PET. Figure 1 shows a patient with multiple FDG-avid bone marrow lesions, which were missed by undirected biopsy.

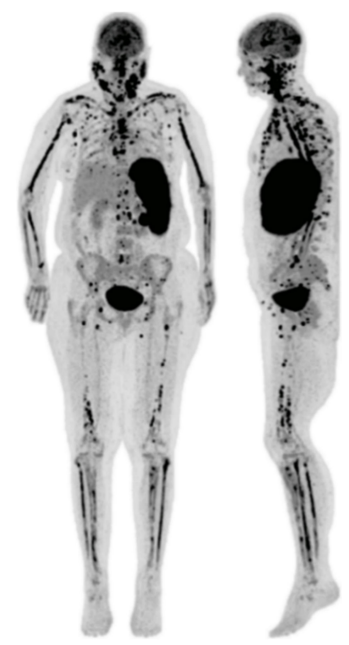

(a)

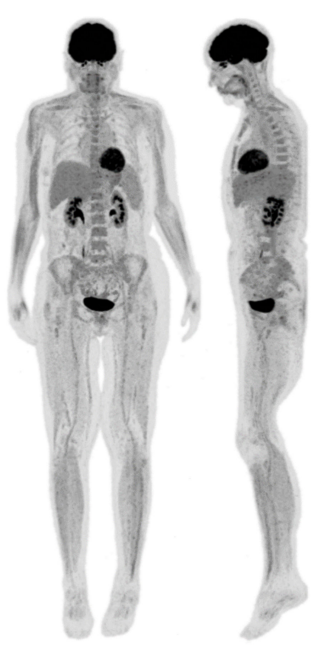

(b)

Figure 1. Female diffuse large B-cell lymphoma (DLBCL) patient with multifocal bone marrow involvement at baseline ${ }^{18}$ F-fluorodeoxyglucose (FDG)-positron emission tomography (PET) (a), which was missed by undirected bone marrow biopsy and remitted completely after six cycles of chemoimmunotherapy (b). 


\section{Early Response Assessment}

In 2009, the so-called Deauville score was introduced to meet the growing need for simple and reproducible PET interpretation in the setting of early response assessment [43]. Based on a visual comparison of lesional FDG uptake with that in the reference regions mediastinal blood pool and liver, it classifies residual tissue from 1 to 5 (Table 1). Several trials have shown superior accuracy and inter-observer agreement of PET-based lymphoma response assessment when using the Deauville criteria and contributed to a rapid integration of the proposed method into reporting routine. Importantly, graded assessment made interpretation more flexible, as this approach allows adjustment of the cut-off between positive and negative results depending on the clinical context.

Table 1. Deauville five-point scale for therapy stratification in patients with FDG-avid lymphomas.

\begin{tabular}{|c|c|c|}
\hline Score & Criteria & Interpretation * \\
\hline 1 & No FDG uptake & \multirow{3}{*}{$\mathrm{CR}$} \\
\hline 2 & FDG uptake lower than or equal to the mediastinal blood pool & \\
\hline 3 & FDG uptake higher than the mediastinal blood pool but lower or equal to liver & \\
\hline 4 & FDG uptake moderately increased compared to the liver & \multirow[b]{2}{*}{$\mathrm{PR} / \mathrm{SD} / \mathrm{PD}$} \\
\hline 5 & $\begin{array}{l}\text { FDG uptake markedly increased compared to the liver and/or new sites } \\
\text { of disease }\end{array}$ & \\
\hline
\end{tabular}

\subsection{Hodgkin Lymphoma}

The key question of studies on early-stage Hodgkin lymphoma has been whether irradiation can be abandoned in the case of complete metabolic response after chemotherapy. In the U.K. RAPID trial [44], 602 stage IA and IIA patients without bulky mediastinal disease underwent PET imaging after three cycles of ABVD. Individuals with a negative PET scan, defined by Deauville scores 1 and 2 , were randomly assigned to no further treatment or $30 \mathrm{~Gy}$ of involved-field irradiation. At a median follow-up of 60 months, patients receiving radiotherapy had a 3-year PFS of $94.6 \%$ compared to $90.8 \%$ in the non-irradiated group. The study did not prove non-inferiority of chemotherapy alone, as it was designed to exclude a difference in 3-year PFS of more than 7\%. Thus, based on the data available thus far, we would not generally recommend omitting consolidative radiotherapy in PET-negative individuals after three courses of ABVD.

The H10 trial randomized 1950 patients with limited-stage favorable and unfavorable Hodgkin lymphoma to PET-guided or standard treatment with three to four cycles of ABVD plus involved-node radiotherapy [4]. In the experimental arm, PET scans were performed after two courses of chemotherapy (PET-2) and evaluated using the mediastinal blood pool as cut-off. Individuals with positive PET-2 received two cycles of eBEACOPP followed by involved-node radiotherapy, which resulted in a significantly improved 5-year PFS (90.6\%) compared to standard treatment (77.4\%). After a second randomization, PET-negative individuals either underwent combined-modality treatment or continued with ABVD alone. The latter arm had to be terminated after preplanned interim analysis due to a high number of relapses with the strategy omitting irradiation. Here again, the omission of radiotherapy in PET-negative patients appeared questionable.

Finally, the German Hodgkin Study Group (GHSG) conducted HD16 as a PET-driven trial for early-stage Hodgkin lymphoma [45]. In this study, patients either received standard combined-modality treatment with two courses of ABVD plus $20 \mathrm{~Gy}$ of involved-field radiotherapy or were assigned to the experimental arm where PET-negative individuals underwent no further treatment after chemotherapy. Any residual tissue showing an FDG uptake greater than the mediastinal blood pool was rated PET-positive. At a median follow-up of 45 months, PET-negative patients after combined-modality treatment had a 5-year PFS of $93.4 \%$ versus $86.1 \%$ with ABVD alone. Since PET-guided omission of 
irradiation resulted in worse disease control, the primary study objective was not achieved. However, among the 693 subjects receiving combined-modality treatment, PET-2 was predictive for therapy failure with a 5-year PFS of 93.2\% in PET-negative patients versus $88.4 \%$ in the PET-positive group.

Based on the published data, radiotherapy should be generally recommended in limited-stage favorable Hodgkin lymphoma after treatment with two cycles of ABVD. Moreover, as revealed by the H10 trial, an intensification of therapy to eBEACOPP must be considered in patients with positive PET results. For intermediate-stage disease, the question for or against irradiation after two cycles of eBEACOPP and two courses ABVD has not yet been resolved. Here, we excitedly await the final results of the GHSG HD17 trial.

In advanced-stage Hodgkin lymphoma, several large studies strongly support the use of FDG-PET for tailoring treatment intensity. The RATHL trial included 1214 patients with stage IIB to IV or high-risk stage IIA disease and tested omission of bleomycin in ABVD cycles three to six after negative PET-2 using the liver as cut-off for PET interpretation [6]. Although results fell short of the prespecified non-inferiority margin, it should be noted that de-escalation of chemotherapy reduced the incidence of pulmonary side-effects without significant loss in efficacy. Individuals with Deauville scores 4 and 5 received either an accelerated BEACOPP version or eBEACOPP and had a 3-year PFS of $67.5 \%$. Quite similar results emerged from the Italian phase III HD 0607 study, where treatment was escalated to BEACOPP in the case of positive PET-2. For these patients, the investigators reported a 3-year PFS of 57\% [46]. The Lymphoma Study Association AHL2011 study examined de-escalation to ABVD in PET-negative patients after two cycles of BEACOPP and reported a 5-year PFS of $85.7 \%$ in the PET-driven arm versus $86.2 \%$ for continued treatment with BEACOPP $(p=0.65)$ [47]. Therefore, Casasnovas et al. concluded that FDG-PET after two cycles of induction BEACOPP can safely guide therapy in advanced-stage Hodgkin lymphoma and allows for the switching to ABVD in early responders without impairment of disease control.

Another de-escalation strategy was examined in the GHSG HD18 trial on advanced-stage Hodgkin lymphoma [7]. In patients receiving eBEACOPP from the beginning, negative PET-2 allowed shortening of treatment from six or eight to only four courses eBEACOPP, with a 5-year PFS of 90.8\% and 92.2\%, respectively. Importantly, severe infections and organ toxicities occurred significantly less often in subjects receiving four cycles of eBEACOPP. To avoid undertreatment, patients in the HD18 trial were randomized, rating a Deauville score of 3 as PET-positive. However, a further analysis revealed that only Deauville scores of 4 or higher signify a relevant risk regarding survival for individuals treated with eBEACOPP upfront, whereas Deauville scores of 1, 2, and 3 should be considered PET-negative [48].

\section{2. $D L B C L$}

In aggressive non-Hodgkin lymphoma, there are only few randomized studies investigating the role of interim PET as an early biomarker for treatment success or failure. The vast majority of trials on DLBCL have examined whether PET-positive patients benefit from therapy escalation. Depending on the timing of PET imaging, treatment was adapted after two to four therapy courses. However, differences in image evaluation and the absence of a control group made it difficult to draw definitive conclusions regarding potential benefits of PET-guided treatment for this lymphoma subset.

In their congress abstract on a study comprising 65 patients with early-stage DLBCL [49], Canadian researchers reported about the value of FDG-PET after three courses R-CHOP. Individuals with positive PET results received a fourth chemoimmunotherapy cycle instead of standard irradiation and were observed to have a superior 3-year PFS of $92 \%$ versus $60 \%$ when using radiotherapy alone. The German PETAL trial calculated the percentage change in maximum standardized uptake value $\left(S U V_{\max }\right)$ between baseline and follow-up $\left(\triangle S U V_{\max }\right)$ for response stratification after two courses of R-CHOP and demonstrated semi-quantitative interpretation to be superior as compared with visual assessment [17,18]. Most of the 812 non-Hodgkin lymphoma patients recruited had DLBCL. All individuals with CD20-positive lymphoma and negative PET-2 were randomly assigned to four more cycles of R-CHOP either with or without two additional rituximab doses. Because the latter did 
not influence clinical outcome, therapy can be limited to six cycles of R-CHOP in the case of negative PET-2 without a loss of efficacy. In contrast, PET positivity was an independent biomarker for poor outcome that could not, however, be improved by treatment intensification.

Another prospective study on DLBCL, the PET-guided GAINED trial, compared obinutuzumab to rituximab plus chemotherapy in treatment-naïve patients younger than 60 years [50]. Individuals showing an early good response received the scheduled immunochemotherapy according to initial randomization, whereas slowly responding patients were treated with two courses of high-dose methotrexate followed by autologous stem-cell transplantation. Non-responders underwent salvage treatment according to local investigators. Based on the exploratory results of the LNH2007-3B study [51], PET positivity was defined as a decline of $\mathrm{SUV}_{\max }$ in an FDG-avid target lesion of at least $66 \%$ or $70 \%$ from baseline to PET after 2 and 4 cycles of chemotherapy, respectively. This trial aimed to validate the $\Delta \mathrm{SUV}_{\max }$-driven consolidation in young patients with high-risk disease.

Finally, a recent analysis including 1977 DLBCL patients from different trials showed that FDG-PET is able to clearly discriminate between responding and non-responding individuals after two, three, or four chemotherapy cycles, while the optimal timing for identification of responders is after two courses [52]. Moreover, the authors recommended PET scanning after four cycles to identify poorly responding patients. Therefore, FDG-PET following chemotherapy courses two and four appears most suitable for future response-adapted trials and therapy regimens in aggressive non-Hodgkin lymphoma.

\section{Late Response Evaluation}

Before the era of FDG-PET, CT imaging was the standard modality for end-of-treatment stratification after chemotherapy. However, CT evaluation suffered from the inability of distinguishing between fibrotic masses and active residual lymphoma tissue, causing high rates of unconfirmed response [53]. Since the late 1990s, a number of studies have consistently demonstrated the high NPV of end-of-treatment PET and underlined its value for this application, particularly in Hodgkin lymphoma [54-60]. Spanish researchers examined 37 subjects with follicular lymphoma, as well as 72 Hodgkin lymphoma and 72 DLBCL patients, in order to compare the diagnostic performance of $\mathrm{CT}$ and FDG-PET/CT [13]. While CT was concordant with the defined reference methods in only $78 \%$ of cases, FDG-PET/CT showed an excellent agreement rate of $97.8 \%$. In addition, PET imaging may be used during follow-up in certain situations. Here, it should be kept in mind that the value of both negative and positive results is limited. Even though FDG-PET might be able to detect relapses earlier than conventional imaging, it has been reported that only one- to two-thirds of positive scans actually indicate relapse and that that there is a significant number of false-negative results in this setting [60-63]. Moreover, the cost-effectiveness of routine PET scanning during follow-up could not be demonstrated [64]. This is why we recommend restricting the use of FDG-PET to selected cases, such as suspected relapse.

\subsection{Hodgkin Lymphoma}

In the GHSG HD15 trial on advanced-stage Hodgkin lymphoma, FDG-PET showed a NPV of $94.1 \%$ for tumor recurrence after BEACOPP chemotherapy [59]. The 4-year PFS of PET-negative patients who did not receive further treatment was 91.5\% [65]. As a result of the HD15 study, radiotherapy is limited to PET-positive residual tissue in advanced-stage Hodgkin lymphoma after eBEACOPP therapy. Moreover, recently presented data have shown that consolidative irradiation might also be omitted in advanced-stage disease after treatment with ABVD [66]. Nevertheless, it is important to keep in mind that the positive predictive value of end-of-treatment PET is generally much lower than its NPV and that most PET-positive individuals stay disease-free after receiving additional radiotherapy, at least in early-stage Hodgkin lymphoma after ABVD and in advanced-stage disease treated with eBEACOPP. 


\section{2. $D L B C L$}

Importantly, PET positivity after completion of R-CHOP therapy has to be interpreted as a sign of unfavorable prognosis in all stages of DLBCL. The prospective Swiss Group for Clinical Cancer Research 38/07 trial reported a significantly lower event-free survival of $48 \%$ in PET-positive patients versus $74 \%$ for those with negative FDG-PET after six courses of dose-dense R-CHOP (R-CHOP-14) [14]. In a population-based Canadian study, irradiation of PET-positive residual tissue after chemoimmunotherapy was shown to substantially improve clinical outcome so that the prognosis of subjects with positive and negative end-of-treatment PET were on a comparable level [15]. These observations could be confirmed by the interim analysis of the prospective German OPTIMAL $>60$ trial for patients with aggressive CD20-positive non-Hodgkin lymphoma [16]. Because this study had no randomization regarding FDG-PET, historic data from the very similar RICOVER-60 study are used for comparison. The latter found that individuals older than 60 years benefit additionally from irradiating former lymphoma bulk after six cycles of (R-)CHOP-14. According to the OPTIMAL $>60$ interim analysis, consolidating radiotherapy in the case of PET-positive bulky disease seems to have a positive effect on survival. Moreover, the Canadian and German data suggest that irradiation can be omitted in $42 \%$ to $60 \%$ of patients with PET-negative bulk.

\section{Recent Advances and Future Directions}

The Deauville score has been applied for therapy stratification in several clinical trials and evolved as an established method for monitoring response to treatment. However, there are ongoing discussions on how to interpret FDG uptake. Barrington et al. recently conducted a subsidiary analysis of the U.K. RAPID study for Hodgkin lymphoma patients and reported that a Deauville score of 5 was associated with an inferior outcome in their trial, where score 5 was defined quantitatively as three or more times the maximum liver uptake [67]. In the GHSG trials HD16 and HD18, Deauville score 3 proved not to be prognostic for progression or relapse, whereas Deauville score 4 did. Even though the majority of individuals with a Deauville score of 4 are cured, these patients show significantly impaired PFS and OS. Similar findings were reported for DLBCL [52]. This is why we recommend interpreting Deauville scores 4 and 5 as positive whenever cure is the primary aim.

Several working groups have recognized quantitative measures as an important tool in staging and response assessment, for instance $S U V_{\max }$ or $\Delta S U V_{\max }$. Studies investigating the role of $\Delta S U V_{\max }$ demonstrated its usefulness for response stratification in both Hodgkin lymphoma and DLBCL $[68,69]$. Additionally, FDG-PET provides biomarkers such as the metabolic tumor volume (MTV) or total lesion glycolysis (TLG), which incorporate information concerning tumor burden and disease activity. Cottereau et al. reported that the MTV improves baseline risk stratification of patients with early-stage Hodgkin lymphoma as compared to currently used staging systems [70]. Interestingly, individuals with early-stage unfavorable disease can even be subdivided into low- and high-risk categories based on the MTV and TLG, as shown elsewhere [71]. A retrospective analysis including 310 patients identified that pretreatment MTV is also a predictive factor for early response to eBEACOPP after two cycles of chemotherapy in advanced-stage Hodgkin lymphoma [72]. Moreover, metabolic measures were reported to have a prognostic value in non-Hodgkin lymphoma. Mikhaeel et al. demonstrated that MTV at staging is an important prognostic factor for DLBCL and that combining MTV with results of early PET response assessment improves the predictive power [73]. Similar findings emerged from a recently published analysis including 510 DLBCL patients treated within the PET-guided therapy optimization trial PETAL [74]. Interestingly, it has been also shown that MTV is a valid prognosticator in elderly individuals with DLBCL receiving R-CHOP. A study by Vercellino and colleagues found high pretreatment MTV to be significantly associated with inferior PFS and OS in this group [75]. Including patients from the LNH073B study, a French working group additionally examined the role of radiomic features characterizing lesion dissemination and reported that combining them with baseline MTV further improves risk stratification in DLBCL patients [76]. However, MTV calculation was carried out rather inconsistently in different working groups, which used both adaptive and fixed thresholds 
(Figure 2, Table 2). A recent review on the increasing importance of MTV addressed the need for standardization and pointed out that further analyses are needed to set common criteria [77]. Up until now, tumor delineation has been significantly more time-consuming in advanced-stage disease than in patients with fewer lesions. The application of machine learning and artificial intelligence can be expected to optimize complex workflows and will open up new perspectives in the future.

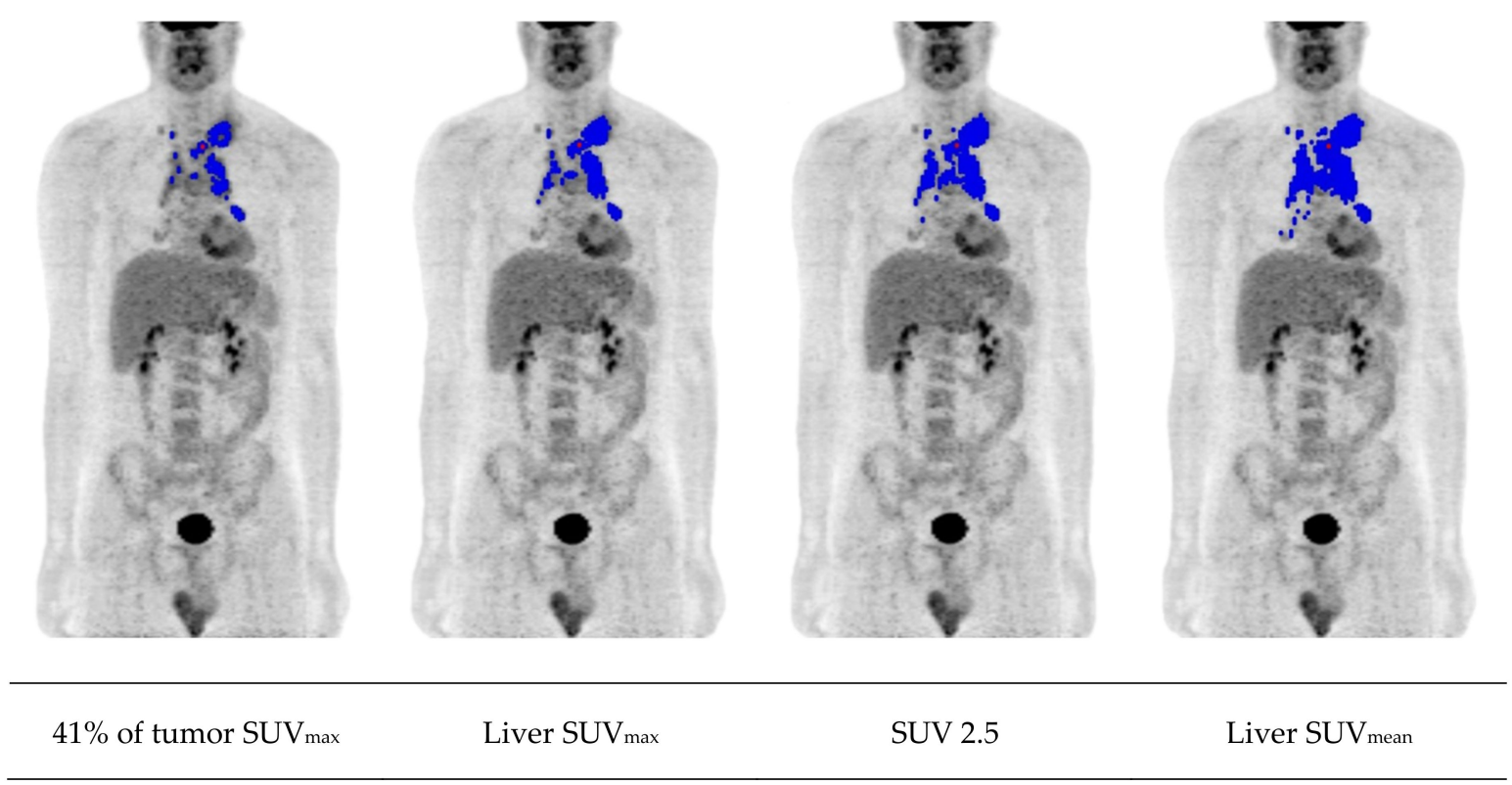

Figure 2. Metabolic tumor volume (MTV) measurement in a patient with advanced-stage Hodgkin lymphoma based on different thresholding methods. SUV, standardized uptake value; SUV $\max$, maximum SUV; SUV mean, mean SUV.

Table 2. Common approaches for MTV calculation with their main characteristics.

\begin{tabular}{ccc}
\hline Threshold & Advantages & Disadvantages \\
\hline $\begin{array}{c}\text { Fixed absolute (e.g., SUV 2.5 } \\
\text { or 4.0) }\end{array}$ & High reproducibility & $\begin{array}{c}\text { Overestimation if tumor lies adjacent to areas of } \\
\text { high physiologic uptake }\end{array}$ \\
\cline { 2 - 3 } $\begin{array}{c}\text { Reference regions (e.g., liver } \\
\text { or mediastinum)* }\end{array}$ & $\begin{array}{c}\text { Adjusted to patient } \\
\text { and scan }\end{array}$ & $\begin{array}{c}\text { Underestimation in tumors that have many } \\
\text { voxels with an uptake less than the threshold }\end{array}$ \\
\cline { 2 - 3 } $\begin{array}{c}\text { Fixed relative (e.g., } 41 \% \text { of } \\
\text { tumor SUVmax) }\end{array}$ & Observer-independence & Mow availability on commercial software \\
\cline { 2 - 3 } & $\begin{array}{c}\text { Obverestimation in case of low } \\
\text { lesion-to-background ratio }\end{array}$ \\
\hline $\begin{array}{c}\text { Adaptive (e.g., } \\
\text { signal-to-background ratio) }\end{array}$ & $\begin{array}{c}\text { Adjusted to patient } \\
\text { and scan }\end{array}$ & $\begin{array}{c}\text { Underestimation of tumors with heterogeneous } \\
\text { uptake and high SUVmax }\end{array}$ \\
\cline { 2 - 3 }
\end{tabular}

* Thresholding method proposed by the PET Response Criteria in Solid Tumors (PERCIST) [78].

It needs to be kept in mind that the reliability of visual and quantitative response assessment can be impaired by inconsistent PET scanning protocols and image reconstruction methods [79]. Intravenous CT contrast media were found to affect PET images quantitatively due to an overestimation of attenuation factors in contrast-enhanced anatomic structure. This may have clinical consequences, particularly for response assessment, as the uptake values of lymphoma tissue rise less sharply than in the reference regions commonly used for PET interpretation [80]. Even though standardization 
is still lacking, quantitative FDG-PET has the potential to substantially improve prognostication in lymphoma. An integration of metabolic measures into clinical trials is currently planned by several working groups and will provide further evidence.

Over recent years, PET using FDG has brought many advances in the diagnosis and treatment of lymphoma patients, but there will most probably be a demand for more specific tracers other than FDG in future clinical practice. Indeed, the first successful trials with immune checkpoint inhibitors point to a major role for such substances in the first-line treatment of lymphomas [81]. However, formerly established PET response criteria may fail in these novel therapy regimens due to false-positive findings caused by inflammatory changes. Therefore, the so-called RECIL scoring system, a combination of single-dimension measurement and PET criteria, was introduced for response evaluation by consensus of an international working group [82]. Not only new drugs but also the RECIL evaluation need prospective studies to confirm their clinical relevance. In this context, it is worth mentioning that radiolabeled programmed cell death-ligand 1 (PD-L1) antibodies have recently proved to be useful for monitoring therapy-induced changes of PD-L1 expression in preclinical tumor models [83], and first clinical studies on solid malignancies have also demonstrated the feasibility of programmed cell death protein 1 (PD-1)/PD-L1 imaging [84]. Thus, highly specific tracers promise to improve our understanding of the dynamic tumor microenvironment and enable optimization of checkpoint inhibitor-based therapy strategies, not only in solid tumors but also in lymphoma patients. Imaging agents such as the chemokine receptor-targeting ${ }^{68} \mathrm{Ga}$-pentixafor [85] or the microenvironment-reflecting ${ }^{68} \mathrm{Ga}$-labeled fibroblast activation protein inhibitor (FAPI) [86] may offer further tools with which to elucidate the mechanisms of treatment and cure.

\section{Conclusions}

In FDG-avid lymphomas, PET has been established as the standard modality for both diagnosis and therapy monitoring (Table 3). PET-based staging is highly sensitive for detecting lymphoma lesions and therefore plays a crucial role in the context of contemporary treatment strategies. However, it should be noted that the positive predictive value of PET is rather moderate, with numerous non-malignant causes for FDG avidity. Importantly, undirected bone marrow biopsy can be safely omitted in Hodgkin lymphoma patients and individuals with DLBCL where involvement has already been proven by FDG-PET. As the overall predictive value of interim PET was found to be particularly high in Hodgkin lymphoma, it was established earlier in this disease than in other lymphoma subtypes. Personalized medicine is nowadays a reality, since escalation and de-escalation of chemo- and radiotherapy are adapted according to PET results. In aggressive non-Hodgkin lymphoma, baseline and interim PET imaging provide important information for disease prognosis as well. Moreover, end-of-treatment PET seems suitable to define whether a particular patient with DLBCL requires irradiation after chemotherapy or not.

Table 3. Evidence-based recommendations on the use of FDG-PET before, during, and after treatment.

\begin{tabular}{ccc}
\hline Indication & Hodgkin Lymphoma & DLBCL \\
\hline Staging & +++ & +++ \\
Early response assessment & ++ & ++ \\
End-of-treatment & ++ & ++ \\
Follow-up & $+/-$ & $+/-$
\end{tabular}

$*+++$, standard modality; ++ , standard—depending on therapy protocol; $+/-$, optional—recommended in selected cases, e.g., suspected relapse.

Novel imaging-derived biomarkers such as the MTV or TLG may further individualize treatment of lymphomas. Hence, prospective trials are needed to validate the prognostic and predictive value of quantitative PET measures, given their great potential as guides for determining the future management of patients with lymphoma. 
Author Contributions: Initial planning and conceptualization of the review, C.A.V., C.K., and D.H.; writing of the original draft, all authors; proofreading and editing of the final manuscript, all authors. All authors have read and agreed to the published version of the manuscript.

Funding: The present work received no external funding.

Conflicts of Interest: There are no conflicts of interest to declare.

\section{References}

1. Howlader, N.; Noone, A.M.; Krapcho, M.; Miller, D.; Brest, A.; Yu, M.; Ruhl, J.; Tatalovich, Z.; Mariotto, A.; Lewis, D.R.; et al. SEER Cancer Statistics Review, 1975-2016; National Cancer Institute: Bethesda, MD, USA, 2019; Available online: https://seer.cancer.gov/csr/1975_2016/ (accessed on 19 November 2019).

2. Eichenauer, D.A.; Aleman, B.M.P.; André, M.P.E.; Federico, M.; Hutchings, M.; Illidge, T.; Engert, A.; Ladetto, M. Hodgkin lymphoma: ESMO clinical practice guidelines for diagnosis, treatment and follow-up. Ann. Oncol. 2018, 29, iv19-iv29. [CrossRef] [PubMed]

3. Engert, A.; Plütschow, A.; Eich, H.T.; Lohri, A.; Dörken, B.; Borchmann, P.; Berger, B.; Greil, R.; Willborn, K.C.; Wilhelm, M.; et al. Reduced treatment intensity in patients with early-stage Hodgkin's lymphoma. N. Engl. J. Med. 2010, 363, 640-652. [CrossRef] [PubMed]

4. André, M.P.E.; Girinsky, T.; Federico, M.; Reman, O.; Fortpied, C.; Gotti, M.; Casasnovas, O.; Brice, P.; van der Maazen, R.; Re, A.; et al. Early positron emission tomography response-adapted treatment in stage I and II Hodgkin lymphoma: Final results of the randomized EORTC/LYSA/FIL H10 trial. J. Clin. Oncol. 2017, 35, 1786-1794. [CrossRef]

5. Gordon, L.I.; Hong, F.; Fisher, R.I.; Bartlett, N.L.; Connors, J.M.; Gascoyne, R.D.; Wagner, H.; Stiff, P.J.; Cheson, B.D.; Gospodarowicz, M.; et al. Randomized phase III trial of ABVD versus Stanford V with or without radiation therapy in locally extensive and advanced-stage Hodgkin lymphoma: An intergroup study coordinated by the Eastern Cooperative Oncology Group (E2496). J. Clin. Oncol. 2013, 31, 684-691. [CrossRef]

6. Johnson, P.; Federico, M.; Kirkwood, A.; Fosså, A.; Berkahn, L.; Carella, A.; d'Amore, F.; Enblad, G.; Franceschetto, A.; Fulham, M.; et al. Adapted Treatment Guided by Interim PET-CT Scan in Advanced Hodgkin's Lymphoma. N. Engl. J. Med. 2016, 374, 2419-2429. [CrossRef] [PubMed]

7. Borchmann, P.; Goergen, H.; Kobe, C.; Lohri, A.; Greil, R.; Eichenauer, D.A.; Zijlstra, J.M.; Markova, J.; Meissner, J.; Feuring-Buske, M.; et al. PET-guided treatment in patients with advanced-stage Hodgkin's lymphoma (HD18): Final results of an open-label, international, randomised phase 3 trial by the German Hodgkin Study Group. Lancet 2018, 390, 2790-2802. [CrossRef]

8. Kreissl, S.; Goergen, H.; Müller, H.; Meissner, J.; Mehnert, A.; Bürkle, C.; Fuchs, M.; Engert, A.; Behringer, K.; Borchmann, P. Survivors' perspectives on risks and benefits of Hodgkin lymphoma treatment: Results of a survey by the German Hodgkin Study Group. Leuk. Lymphoma 2019, 60, 1389-1398. [CrossRef]

9. Skoetz, N.; Trelle, S.; Rancea, M.; Haverkamp, H.; Diehl, V.; Engert, A.; Borchmann, P. Effect of initial treatment strategy on survival of patients with advanced-stage Hodgkin's lymphoma: A systematic review and network meta-analysis. Lancet Oncol. 2013, 14, 943-952. [CrossRef]

10. Steidl, C.; Connors, J.M.; Gascoyne, R.D. Molecular pathogenesis of Hodgkin's lymphoma: Increasing evidence of the importance of the microenvironment. J. Clin. Oncol. 2011, 29, 1812-1826. [CrossRef]

11. Liu, W.R.; Shipp, M.A. Signaling pathways and immune evasion mechanisms in classical Hodgkin lymphoma. Hematol. Am. Soc. Hematol. Educ. Program 2017, 2017, 310-316. [CrossRef]

12. Swerdlow, S.H.; Campo, E.; Harris, N.L.; Jaffe, E.S.; Pileri, S.A.; Stein,H.; Thiele, J.; Arber, D.A.; Hasserjian, R.P.; Le Beau, M.M.; et al. WHO Classification of Tumours of Haematopoietic and Lymphoid Tissues, Review, 4th ed.; International Agency for Research on Cancer: Lyon, France, 2017.

13. Gómez León, N.; Delgado-Bolton, R.C.; Del Campo Del Val, L.; Cabezas, B.; Arranz, R.; García, M.; Cannata, J.; González Ortega, S.; Pérez Sáez, M.Á.; López-Botet, B.; et al. Multicenter comparison of contrast-enhanced FDG PET/CT and 64-slice multi-detector-row CT for initial staging and response evaluation at the end of treatment in patients with lymphoma. Clin. Nucl. Med. 2017, 42, 595-602. [CrossRef] [PubMed] 
14. Mamot, C.; Klingbiel, D.; Hitz, F.; Renner, C.; Pabst, T.; Driessen, C.; Mey, U.; Pless, M.; Bargetzi, M.; Krasniqi, F.; et al. Final results of a prospective evaluation of the predictive value of interim positron emission tomography in patients with diffuse large B-cell lymphoma treated with R-CHOP-14 (SAKK 38/07). J. Clin. Oncol. 2015, 33, 2523-2529. [CrossRef] [PubMed]

15. Freeman, C.L.; Savage, K.J.; Villa, D.; Scott, D.W.; Srour, L.; Gerrie, A.S.; Brown, M.J.; Slack, G.W.; Farinha, P.; Skinnider, B.; et al. Long-term results of PET-guided radiation therapy in patients with advanced-stage diffuse large B-cell lymphoma treated with R-CHOP in British Columbia. Blood 2017, 130, 823.

16. Pfreundschuh, M.; Christofyllakis, K.; Altmann, B.; Ziepert, M.; Haenel, M.; Viardot, A.; Neubauer, A.; Held, A.; Truemper, L.; Schmidt, C.; et al. Radiotherapy to bulky disease PET-negative after immunochemotherapy in elderly DLBCL patients: Results of a planned interim analysis of the first 187 patients with bulky disease treated in the OPTIMAL > 60 study of the DSHNHL. J. Clin. Oncol. 2017, 35, 7506. [CrossRef]

17. Dührsen, U.; Müller, S.; Hertenstein, B.; Thomssen, H.; Kotzerke, J.; Mesters, R.; Berdel, W.E.; Franzius, C.; Kroschinsky, F.; Weckesser, M.; et al. PETAL trial investigators. Positron emission tomography-guided therapy of aggressive non-Hodgkin lymphomas (PETAL): A multicenter, randomized phase III trial. J. Clin. Oncol. 2018, 36, 2024-2034. [CrossRef]

18. Hüttmann, A.; Rekowski, J.; Müller, S.P.; Hertenstein, B.; Franzius, C.; Mesters, R.; Weckesser, M.; Kroschinsky, F.; Kotzerke, J.; Ganser, A.; et al. Six versus eight doses of rituximab in patients with aggressive B cell lymphoma receiving six cycles of CHOP: Results from the "Positron Emission Tomography-Guided Therapy of Aggressive Non-Hodgkin Lymphomas" (PETAL) trial. Ann. Hematol. 2019, 98, 897-907. [CrossRef]

19. Poeschel, V.; Held, G.; Ziepert, M.; Witzens-Harig, M.; Holte, H.; Thurner, L.; Borchmann, P.; Viardot, A.; Soekler, M.; Keller, U.; et al. Four versus six cycles of CHOP chemotherapy in combination with six applications of rituximab in patients with aggressive B-cell lymphoma with favourable prognosis (FLYER): A randomised, phase 3, non-inferiority trial. Lancet 2020, 394, 2271-2281. [CrossRef]

20. The International Non-Hodgkin's Lymphoma Prognostic Factors Project. A predictive model for aggressive non-Hodgkin's lymphoma. N. Engl. J. Med. 1993, 329, 987-994. [CrossRef]

21. Tilly, H.; Gomes da Silva, M.; Vitolo, U.; Jack, A.; Meignan, M.; Lopez-Guillermo, A.; Walewski, J.; André, M.P.E.; Johnson, P.W.; Pfreundschuh, M.; et al. ESMO Guidelines Committee. Diffuse large B-cell lymphoma (DLBCL): ESMO Clinical Practice Guidelines for diagnosis, treatment and follow-up. Ann. Oncol. 2015, 26, v116-v125. [CrossRef]

22. Pfreundschuh, M.; Schubert, J.; Ziepert, M.; Schmits, R.; Mohren, M.; Lengfelder, E.; Reiser, M.; Nickenig, C.; Clemens, M.; Peter, N.; et al. German High-Grade Non-Hodgkin Lymphoma Study Group (DSHNHL). Six versus eight cycles of bi-weekly CHOP-14 with or without rituximab in elderly patients with aggressive CD20 + B-cell lymphomas: A randomised controlled trial (RICOVER-60). Lancet Oncol. 2008, 9, 105-116. [CrossRef]

23. Held, G.; Murawski, N.; Ziepert, M.; Fleckenstein, J.; Pöschel, V.; Zwick, C.; Bittenbring, J.; Hänel, M.; Wilhelm, S.; Schubert, J.; et al. Role of radiotherapy to bulky disease in elderly patients with aggressive B-cell lymphoma. J. Clin. Oncol. 2014, 32, 1112-1118. [CrossRef] [PubMed]

24. Cheson, B.D.; Fisher, R.I.; Barrington, S.F.; Cavalli, F.; Schwartz, L.H.; Zucca, E.; Lister, T.A. Recommendations for initial evaluation, staging, and response assessment of Hodgkin and non-Hodgkin lymphoma: The Lugano classification. J. Clin. Oncol. 2014, 32, 3059-3068. [CrossRef] [PubMed]

25. Carbone, P.P.; Kaplan, H.S.; Musshoff, K.; Smithers, D.W.; Tubiana, M. Report of the committee on Hodgkin's disease staging classification. Cancer Res. 1971, 31, 1860-1861. [PubMed]

26. Barrington, S.F.; Kirkwood, A.A.; Franceschetto, A.; Fulham, M.J.; Roberts, T.H.; Almquist, H.; Brun, E.; Hjorthaug, K.; Viney, Z.N.; Pike, L.C.; et al. PET-CT for staging and early response: Results from the response-adapted therapy in advanced Hodgkin lymphoma study. Blood 2016, 127, 1531-1538. [CrossRef]

27. Moulin-Romsee, G.; Hindié, E.; Cuenca, X.; Brice, P.; Decaudin, D.; Bénamor, M.; Brière, J.; Anitei, M.; Filmont, J.E.; Sibon, D.; et al. ${ }^{18}$ F-FDG PET/CT bone/bone marrow findings in Hodgkin's lymphoma may circumvent the use of bone marrow trephine biopsy at diagnosis staging. Eur. J. Nucl. Med. Mol. Imaging 2010, 37, 1095-1105. [CrossRef] 
28. El-Galaly, T.C.; d'Amore, F.; Mylam, K.J.; de Nully Brown, P.; Bøgsted, M.; Bukh, A.; Specht, L.; Loft, A.; Iyer, V.; Hjorthaug, K.; et al. Routine bone marrow biopsy has little or no therapeutic consequence for positron emission tomography/computed tomography-staged treatment-naïve patients with Hodgkin lymphoma. J. Clin. Oncol. 2012, 30, 4508-4514. [CrossRef]

29. Weiler-Sagie, M.; Kagna, O.; Dann, E.J.; Ben-Barak, A.; Israel, O. Characterizing bone marrow involvement in Hodgkin's lymphoma by FDG-PET/CT. Eur. J. Nucl. Med. Mol. Imaging 2014, 41, 1133-1140. [CrossRef]

30. Chen-Liang, T.H.; Martin-Santos, T.; Jerez, A.; Senent, L.; Orero, M.T.; Remigia, M.J.; Muiña, B.; Romera, M.; Fernandez-Muñoz, H.; Raya, J.M.; et al. The role of bone marrow biopsy and FDG-PET/CT in identifying bone marrow infiltration in the initial diagnosis of high grade non-Hodgkin B-cell lymphoma and Hodgkin lymphoma. Accuracy in a multicenter series of 372 patients. Am. J. Hematol. 2015, 90, 686-690. [CrossRef]

31. Purz, S.; Mauz-Körholz, C.; Körholz, D.; Hasenclever, D.; Krausse, A.; Sorge, I.; Ruschke, K.; Stiefel, M.; Amthauer, H.; Schober, O.; et al. $\left[{ }^{18} \mathrm{~F}\right]$ fluorodeoxyglucose positron emission tomography for detection of bone marrow involvement in children and adolescents with Hodgkin's lymphoma. J. Clin. Oncol. 2011, 29, 3523-3528. [CrossRef]

32. Voltin, C.A.; Goergen, H.; Baues, C.; Fuchs, M.; Mettler, J.; Kreissl, S.; Oertl, J.; Klaeser, B.; Moccia, A.; Drzezga, A.; et al. Value of bone marrow biopsy in Hodgkin lymphoma patients staged by FDG PET: Results from the German Hodgkin Study Group trials HD16, HD17, and HD18. Ann. Oncol. 2018, 29, 1926-1931. [CrossRef]

33. Pedersen, M.A.; Gormsen, L.C.; Kamper, P.; Wassberg, C.; Andersen, M.D.; d'Amore, A.L.; Barrington, S.F.; Johnson, P.; Hamilton-Dutoit, S.; Amini, R.M.; et al. Focal skeletal FDG uptake indicates poor prognosis in cHL regardless of extent and first-line chemotherapy. Br. J. Haematol. 2019, 186, 431-439. [CrossRef] [PubMed]

34. Adams, H.J.; de Klerk, J.M.; Fijnheer, R.; Heggelman, B.G.; Dubois, S.V.; Nievelstein, R.A.; Kwee, T.C. Variety in bone marrow ${ }^{18}$ F-FDG uptake in Hodgkin lymphoma patients without lymphomatous bone marrow involvement: Does it have an explanation? Nucl. Med. Commun. 2016, 37, 23-29. [CrossRef] [PubMed]

35. Picardi, M.; Soricelli, A.; Grimaldi, F.; Nicolai, E.; Gallamini, A.; Pane, F. Fused FDG-PET/contrast-enhanced CT detects occult subdiaphragmatic involvement of Hodgkin's lymphoma thereby identifying patients requiring six cycles of anthracycline-containing chemotherapy and consolidation radiation of spleen. Ann. Oncol. 2011, 22, 671-680. [CrossRef] [PubMed]

36. Fuertes, S.; Setoain, X.; López-Guillermo, A.; Montserrat, E.; Fuster, D.; Paredes, P.; Lomeña, F.; Pons, F. The value of positron emission tomography/computed tomography (PET/CT) in the staging of diffuse large B-cell lymphoma. Med. Clin. 2007, 129, 688-693. [CrossRef] [PubMed]

37. Raanani, P.; Shasha, Y.; Perry, C.; Metser, U.; Naparstek, E.; Apter, S.; Nagler, A.; Polliack, A.; Ben-Bassat, I.; Even-Sapir, E. Is CT scan still necessary for staging in Hodgkin and non-Hodgkin lymphoma patients in the PET/CT era? Ann. Oncol. 2006, 17, 117-122. [CrossRef]

38. Elstrom, R.L.; Leonard, J.P.; Coleman, M.; Brown, R.K. Combined PET and low-dose, noncontrast CT scanning obviates the need for additional diagnostic contrast-enhanced CT scans in patients undergoing staging or restaging for lymphoma. Ann. Oncol. 2008, 19, 1770-1773. [CrossRef]

39. Cerci, J.J.; Györke, T.; Fanti, S.; Paez, D.; Meneghetti, J.C.; Redondo, F.; Celli, M.; Auewarakul, C.; Rangarajan, V.; Gujral, S.; et al. Combined PET and biopsy evidence of marrow involvement improves prognostic prediction in diffuse large B-cell lymphoma. J. Nucl. Med. 2014, 55, 1591-1597. [CrossRef]

40. Khan, A.B.; Barrington, S.F.; Mikhaeel, N.G.; Hunt, A.A.; Cameron, L.; Morris, T.; Carr, R. PET-CT staging of DLBCL accurately identifies and provides new insight into the clinical significance of bone marrow involvement. Blood 2013, 122, 61-67. [CrossRef]

41. Alzahrani, M.; El-Galaly, T.C.; Hutchings, M.; Hansen, J.W.; Loft, A.; Johnsen, H.E.; Iyer, V.; Wilson, D.; Sehn, L.H.; Savage, K.J.; et al. The value of routine bone marrow biopsy in patients with diffuse large B-cell lymphoma staged with PET/CT: A Danish-Canadian study. Ann. Oncol. 2016, 27, 1095-1099. [CrossRef]

42. Kaddu-Mulindwa, D.; Altmann, B.; Held, G.; Ziepert, M.; Menhart, K.; Grosse, J.; Angel, S.; Stilgenbauer, S.; Pfreundschuh, M.; Herrmann, K.; et al. Role of FDG PET/CT to detect bone marrow involvement in the initial staging of aggressive non-Hodgkin lymphoma. Blood 2019, 134, 2892. [CrossRef]

43. Meignan, M.; Gallamini, A.; Haioun, C. Report on the First International Workshop on Interim-PET-Scan in Lymphoma. Leuk. Lymphoma 2009, 50, 1257-1260. [CrossRef] [PubMed] 
44. Radford, J.; Illidge, T.; Counsell, N.; Hancock, B.; Pettengell, R.; Johnson, P.; Wimperis, J.; Culligan, D.; Popova, B.; Smith, P.; et al. Results of a trial of PET-directed therapy for early-stage Hodgkin's lymphoma. N. Engl. J. Med. 2015, 372, 1598-1607. [CrossRef] [PubMed]

45. Fuchs, M.; Goergen, H.; Kobe, C.; Kuhnert, G.; Lohri, A.; Greil, R.; Sasse, S.; Topp, M.S.; Schäfer, E.; Hertenstein, B.; et al. Positron emission tomography-guided treatment in early-stage favorable hodgkin lymphoma: Final results of the international, randomized phase III HD16 trial by the German Hodgkin Study Group. J. Clin. Oncol. 2019, 37, 2835-2845. [CrossRef] [PubMed]

46. Gallamini, A.; Tarella, C.; Viviani, S.; Rossi, A.; Patti, C.; Mulé, A.; Picardi, M.; Romano, A.; Cantonetti, M.; La Nasa, G.; et al. Early chemotherapy intensification with escalated beacopp in patients with advanced-stage Hodgkin lymphoma with a positive interim positron emission tomography/computed tomography scan after two ABVD cycles: Long-term results of the GITIL/FIL HD 0607 trial. J. Clin. Oncol. 2018, 36, 454-462. [CrossRef] [PubMed]

47. Casasnovas, R.O.; Bouabdallah, R.; Brice, P.; Lazarovici, J.; Ghesquieres, H.; Stamatoullas, A.; Dupuis, J.; Gac, A.C.; Gastinne, T.; Joly, B.; et al. PET-adapted treatment for newly diagnosed advanced Hodgkin lymphoma (AHL2011): A randomised, multicentre, non-inferiority, phase 3 study. Lancet Oncol. 2019, 20, 202-215. [CrossRef]

48. Kobe, C.; Goergen, H.; Baues, C.; Kuhnert, G.; Voltin, C.A.; Zijlstra, J.; Hoekstra, O.; Mettler, J.; Drzezga, A.; Engert, A.; et al. Outcome-based interpretation of early interim PET in advanced-stage Hodgkin lymphoma. Blood 2018, 132, 2273-2279. [CrossRef]

49. Sehn, L.H.; Savage, K.J.; Hoskins, P.; Klasa, R.; Shenkier, T.; Gascoyne, R.D.; Voss, N.; Wilson, D.; Connors, J. Limited-stage DLBCL patients with a negative PET scan following three cycles of R-CHOP have an excellent outcome following abbreviated immuno-chemotherapy alone. Ann. Oncol. 2008, 19, 99.

50. Casasnovas, R.O.; Salles, G.A.; Oberic, L.; Bodet-Milin, C.; Briere, J.; Morschhauser, F.; Tilly, H.; Ribrag, V.; Lamy, T.; Thieblemont, C.; et al. Obinutuzumab versus rituximab in combination with ACVBP-14 or CHOP-14 following a PET-driven strategy in Aa-IPI 1-3 DLBCL patients ( $<60$ years): Third planned interim and final analyses of the gained trial. Blood 2017, 626, 190.

51. Casasnovas, R.O.; Ysebaert, L.; Thieblemont, C.; Bachy, E.; Feugier, P.; Delmer, A.; Tricot, S.; Gabarre, J.; André, M.P.E.; Fruchart, C.; et al. FDG-PET-driven consolidation strategy in diffuse large B-cell lymphoma: Final results of a randomized phase 2 study. Blood 2017, 130, 1315-1326. [CrossRef]

52. Eertink, J.J.; Burggraaff, C.N.; Heymans, M.W.; Barrington, S.F.; Mikhaeel, G.; Dührsen, U.; Hüttmann, A.; Ceriani, L.; Zucca, E.; Carr, R.; et al. The optimal timing of interim ${ }^{18}$ F-FDG PET in diffuse large B-cell lymphoma: An individual patient data meta-analysis by the Petra consortium. Blood 2019, 134, 487. [CrossRef]

53. Canellos, G.P. Residual mass in lymphoma may not be residual disease. J. Clin. Oncol. 1988, 6, 931-933. [CrossRef] [PubMed]

54. Jerusalem, G.; Beguin, Y.; Fassotte, M.F.; Najjar, F.; Paulus, P.; Rigo, P.; Fillet, G. Whole-body positron emission tomography using ${ }^{18} \mathrm{~F}$-fluorodeoxyglucose for posttreatment evaluation in Hodgkin's disease and non-Hodgkin's lymphoma has higher diagnostic and prognostic value than classical computed tomography scan imaging. Blood 1999, 94, 429-433. [CrossRef] [PubMed]

55. De Wit, M.; Bohuslavizki, K.H.; Buchert, R.; Bumann, D.; Clausen, M.; Hossfeld, D.K. ${ }^{18}$ FDG-PET following treatment as valid predictor for disease-free survival in Hodgkin's lymphoma. Ann. Oncol. 2001, 12, $29-37$. [CrossRef]

56. Spaepen, K.; Stroobants, S.; Dupont, P.; Thomas, J.; Vandenberghe, P.; Balzarini, J.; De Wolf-Peeters, C.; Mortelmans, L.; Verhoef, G. Can positron emission tomography with $\left[{ }^{18} \mathrm{~F}\right]$-fluorodeoxyglucose after first-line treatment distinguish Hodgkin's disease patients who need additional therapy from others in whom additional therapy would mean avoidable toxicity? Br. J. Haematol. 2001, 115, 272-278. [CrossRef] [PubMed]

57. Weihrauch, M.R.; Re, D.; Scheidhauer, K.; Ansén, S.; Dietlein, M.; Bischoff, S.; Bohlen, H.; Wolf, J.; Schicha, H.; Diehl, V.; et al. Thoracic positron emission tomography using ${ }^{18} \mathrm{~F}$-fluorodeoxyglucose for the evaluation of residual mediastinal Hodgkin disease. Blood 2001, 98, 2930-2934. [CrossRef]

58. Schaefer, N.G.; Taverna, C.; Strobel, K.; Wastl, C.; Kurrer, M.; Hany, T.F. Hodgkin disease: Diagnostic value of FDG PET/CT after first-line therapy-Is biopsy of FDG-avid lesions still needed? Radiology 2007, 244, 257-262. [CrossRef] [PubMed] 
59. Kobe, C.; Dietlein, M.; Franklin, J.; Markova, J.; Lohri, A.; Amthauer, H.; Klutmann, S.; Knapp, W.H.; Zijlstra, J.M.; Bockisch, A.; et al. Positron emission tomography has a high negative predictive value for progression or early relapse for patients with residual disease after first-line chemotherapy in advanced-stage Hodgkin lymphoma. Blood 2008, 112, 3989-3994. [CrossRef]

60. Markova, J.; Kahraman, D.; Kobe, C.; Skopalova, M.; Mocikova, H.; Klaskova, K.; Dedeckova, K.; Eich, H.T.; Böll, B.; Dietlein, M.; et al. Role of $\left[{ }^{18} \mathrm{~F}\right]$-fluoro-2-deoxy-D-glucose positron emission tomography in early and late therapy assessment of patients with advanced Hodgkin lymphoma treated with bleomycin, etoposide, adriamycin, cyclophosphamide, vincristine, procarbazine and prednisone. Leuk. Lymphoma 2012, 53, 64-70. [CrossRef]

61. Jerusalem, G.; Beguin, Y.; Fassotte, M.F.; Belhocine, T.; Hustinx, R.; Rigo, P.; Fillet, G. Early detection of relapse by whole-body positron emission tomography in the follow-up of patients with Hodgkin's disease. Ann. Oncol. 2003, 14, 123-130. [CrossRef]

62. Mocikova, H.; Obrtlikova, P.; Vackova, B.; Trneny, M. Positron emission tomography at the end of first-line therapy and during follow-up in patients with Hodgkin lymphoma: A retrospective study. Ann. Oncol. 2010, 21, 1222-1227. [CrossRef]

63. Zinzani, P.L.; Stefoni, V.; Tani, M.; Fanti, S.; Musuraca, G.; Castellucci, P.; Marchi, E.; Fina, M.; Ambrosini, V.; Pellegrini, C.; et al. Role of $\left[{ }^{18} \mathrm{~F}\right]$ fluorodeoxyglucose positron emission tomography scan in the follow-up of lymphoma. J. Clin. Oncol. 2009, 27, 1781-1787. [CrossRef] [PubMed]

64. Picardi, M.; Pugliese, N.; Cirillo, M.; Zeppa, P.; Cozzolino, I.; Ciancia, G.; Pettinato, G.; Salvatore, C.; Quintarelli, C.; Pane, F. Advanced-stage Hodgkin lymphoma: US/chest radiography for detection of relapse in patients in first complete remission-A randomized trial of routine surveillance imaging procedures. Radiology 2014, 272, 262-274. [CrossRef] [PubMed]

65. Kobe, C.; Kuhnert, G.; Kahraman, D.; Haverkamp, H.; Eich, H.T.; Franke, M.; Persigehl, T.; Klutmann, S.; Amthauer, H.; Bockisch, A.; et al. Assessment of tumor size reduction improves outcome prediction of positron emission tomography/computed tomography after chemotherapy in advanced-stage Hodgkin lymphoma. J. Clin. Oncol. 2014, 32, 1776-1781. [CrossRef] [PubMed]

66. Gallamini, A.; Rossi, A.; Patti, C.; Picardi, M.; Romano, A.; Cantonetti, M.; Oppi, S.; Viviani, S.; Bolis, S.; Trentin, L.; et al. Consolidation radiotherapy could be omitted in advanced hodgkin lymphoma with large nodal mass in complete metabolic response after ABVD. Final analysis of the randomized HD0607 trial. Hematol. Oncol. 2019, 37, 99. [CrossRef]

67. Barrington, S.F.; Phillips, E.H.; Counsell, N.; Hancock, B.; Pettengell, R.; Johnson, P.; Townsend, W.; Culligan, D.; Popova, B.; Clifton-Hadley, L.; et al. Positron emission tomography score has greater prognostic significance than pretreatment risk stratification in early-stage hodgkin lymphoma in the UK RAPID Study. J. Clin. Oncol. 2019, 37, 1732-1741. [CrossRef]

68. Itti, E.; Meignan, M.; Berriolo-Riedinger, A.; Biggi, A.; Cashen, A.F.; Véra, P.; Tilly, H.; Siegel, B.A.; Gallamini, A.; Casasnovas, R.O.; et al. An international confirmatory study of the prognostic value of early PET/CT in diffuse large B-cell lymphoma: Comparison between Deauville criteria and $\triangle$ SUVmax. Eur. J. Nucl. Med. Mol. Imaging 2013, 40, 1312-1320. [CrossRef]

69. Rossi, C.; Kanoun, S.; Berriolo-Riedinger, A.; Dygai-Cochet, I.; Humbert, O.; Legouge, C.; Chrétien, M.L.; Bastie, J.N.; Brunotte, F.; Casasnovas, R.O. Interim ${ }^{18}$ F-FDG PET SUVmax reduction is superior to visual analysis in predicting outcome early in Hodgkin lymphoma patients. J. Nucl. Med. 2014, 55, 569-573. [CrossRef]

70. Cottereau, A.S.; Versari, A.; Loft, A.; Casasnovas, O.; Bellei, M.; Ricci, R.; Bardet, S.; Castagnoli, A.; Brice, P.; Raemaekers, J.; et al. Prognostic value of baseline metabolic tumor volume in early-stage Hodgkin lymphoma in the standard arm of the H10 trial. Blood 2018, 131, 1456-1463. [CrossRef]

71. Akhtari, M.; Milgrom, S.A.; Pinnix, C.C.; Reddy, J.P.; Dong, W.; Smith, G.L.; Mawlawi, O.; Abou Yehia, Z.; Gunther, J.; Osborne, E.M.; et al. Reclassifying patients with early-stage Hodgkin lymphoma based on functional radiographic markers at presentation. Blood 2018, 131, 84-94. [CrossRef]

72. Mettler, J.; Müller, H.; Voltin, C.A.; Baues, C.; Klaeser, B.; Moccia, A.; Borchmann, P.; Engert, A.; Kuhnert, G.; Drzezga, A.; et al. Metabolic tumor volume for response prediction in advanced-stage hodgkin lymphoma. J. Nucl. Med. 2019, 60, 207-211. [CrossRef] 
73. Mikhaeel, N.G.; Smith, D.; Dunn, J.T.; Phillips, M.; Møller, H.; Fields, P.A.; Wrench, D.; Barrington, S.F. Combination of baseline metabolic tumour volume and early response on PET/CT improves progression-free survival prediction in DLBCL. Eur. J. Nucl. Med. Mol. Imaging 2016, 43, 1209-1219. [CrossRef] [PubMed]

74. Schmitz, C.; Hüttmann, A.; Müller, S.P.; Hanoun, M.; Boellaard, R.; Brinkmann, M.; Jöckel, K.H.; Dührsen, U.; Rekowski, J. Dynamic risk assessment based on positron emission tomography scanning in diffuse large B-cell lymphoma: Post-hoc analysis from the PETAL trial. Eur. J. Cancer 2019, 124, 25-36. [CrossRef] [PubMed]

75. Vercellino, L.; Cottereau, A.S.; Casasnovas, R.O.; Tilly, H.; Feugier, P.; Chartier, L.; Fruchart, C.; Roulin, L.; Obéric, L.; Pica, G.M.; et al. High total metabolic tumor volume at baseline allows discrimination of survival even in patients aged 60 to 80 years responding to R-CHOP. Blood 2020. [CrossRef] [PubMed]

76. Cottereau, A.S.; Nioche, C.; Dirand, A.S.; Clerc, J.; Morschhauser, F.; Casasnovas, O.; Meignan, M.A.; Buvat, I. ${ }^{18}$ F-FDG-PET dissemination features in diffuse large B cell lymphoma are prognostic of outcome. J. Nucl. Med. 2019, 61, 40-45. [CrossRef]

77. Barrington, S.F.; Meignan, M. Time to prepare for risk adaptation in lymphoma by standardizing measurement of metabolic tumor burden. J. Nucl. Med. 2019, 60, 1096-1102. [CrossRef]

78. Wahl, R.L.; Jacene, H.; Kasamon, Y.; Lodge, M.A. From RECIST to PERCIST: Evolving considerations for PET response criteria in solid tumors. J. Nucl. Med. 2009, 50, 122S-150S. [CrossRef]

79. Boellaard, R.; Sera, T.; Kaalep, A.; Hoekstra, O.S.; Barrington, S.F.; Zijlstra, J.M. Updating PET/CT performance standards and PET/CT interpretation criteria should go hand in hand. EJNMMI Res. 2019, 9, 95. [CrossRef]

80. Voltin, C.A.; Mettler, J.; Boellaard, R.; Kuhnert, G.; Dietlein, M.; Borchmann, P.; Drzezga, A.; Kobe, C. Quantitative assessment of ${ }^{18}$ F-FDG PET in patients with Hodgkin lymphoma: Is it significantly affected by contrast-enhanced computed tomography attenuation correction? Nucl. Med. Commun. 2019, 40, $249-257$. [CrossRef]

81. Bröckelmann, P.J.; Goergen, H.; Keller, U.; Meissner, J.; Ordemann, R.; Halbsguth, T.V.; Sasse, S.; Sökler, M.; Kerkhoff, A.; Mathas, S.; et al. Nivolumab and AVD for Early-Stage Unfavorable Hodgkin Lymphoma (NIVAHL). Blood 2019, 134, 236. [CrossRef]

82. Younes, A.; Hilden, P.; Coiffier, B.; Hagenbeek, A.; Salles, G.; Wilson, W.; Seymour, J.F.; Kelly, K.; Gribben, J.; Pfreunschuh, M.; et al. International Working Group consensus response evaluation criteria in lymphoma (RECIL 2017). Ann. Oncol. 2017, 28, 1436-1447. [CrossRef]

83. Verhoeff, S.R.; van den Heuvel, M.M.; van Herpen, C.M.L.; Piet, B.; Aarntzen, E.H.J.G.; Heskamp, S. Programmed cell death-1/Ligand-1 PET imaging: A novel tool to optimize immunotherapy? PET Clin. 2020, 15, 35-43. [CrossRef] [PubMed]

84. Heskamp, S.; Hobo, W.; Molkenboer-Kuenen, J.D.; Olive, D.; Oyen, W.J.; Dolstra, H.; Boerman, O.C. Noninvasive imaging of tumor PD-L1 expression using radiolabeled Anti-PD-L1 antibodies. Cancer Res. 2015, 75, 2928-2936. [CrossRef] [PubMed]

85. Wester, H.J.; Keller, U.; Schottelius, M.; Beer, A.; Philipp-Abbrederis, K.; Hoffmann, F.; Šimeček, J.; Gerngross, C.; Lassmann, M.; Herrmann, K.; et al. Disclosing the CXCR4 expression in lymphoproliferative diseases by targeted molecular imaging. Theranostics 2015, 5, 618-630. [CrossRef] [PubMed]

86. Kratochwil, C.; Flechsig, P.; Lindner, T.; Abderrahim, L.; Altmann, A.; Mier, W.; Adeberg, S.; Rathke, H.; Röhrich, M.; Winter, H.; et al. ${ }^{68}$ Ga-FAPI PET/CT: Tracer uptake in 28 different kinds of cancer. J. Nucl. Med. 2019, 60, 801-805. [CrossRef]

(C) 2020 by the authors. Licensee MDPI, Basel, Switzerland. This article is an open access article distributed under the terms and conditions of the Creative Commons Attribution (CC BY) license (http://creativecommons.org/licenses/by/4.0/). 